\title{
The importance of staging systems for the determination of prognosis of well-differentiated thyroid cancer
}

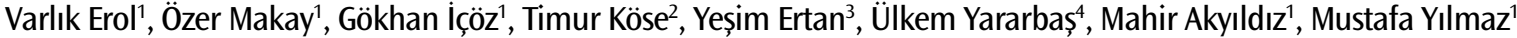

\section{ABSTRACT}

'Department of General Surgery, Ege University Faculty of Medicine, İzmir, Turkey ${ }^{2}$ Department of Biostatistics, Ege University Faculty of Medicine, İzmir, Turkey

${ }^{3}$ Department of Pathology, Ege University Faculty of Medicine, Izmir, Turkey

${ }^{4}$ Department of Nuclear Medicine, Ege University Faculty of Medicine, Izmir, Turkey

This study was presented at the $18^{\text {th }}$ National Surgical Congress as an oral presentation, 23-27 May 2012, Izmir, Turkey

\section{Address for Correspondence Dr. Varlık Erol} Department of General Surgery, Ege University Faculty of Medicine, İzir, Turkey Phone.: +90 2323904020 e-mail: varlikerol@gmail.com

Received: 08.10.2012 Accepted: 09.01.2013

(C) Copyright 2013 by Turkish Surgical Association

Available online at www.ulusalcerrahidergisi.org
Objective: In this study, we aimed to determine the significance of the staging systems (EORTC, De Groot, MACIS, and TNM) on the prognosis of well-differentiated thyroid cancer patients who underwent surgery in our clinics.

Material and Methods: This retrospective study included 181 patients who were operated between December 1995-December 2007, with a diagnosis of thyroid cancer. In order to obtain data related to cancer staging, a computer program for PDA was developed to facilitate parameter recording. Survival analysis was performed. The findings were compared to the predicted rates by the staging systems.

Results: According to the De Groot staging system, stage 1 and stage 2 patients' results were compatible, but stage 3 and 4 patients' results were different (stage $3 ; 87 \%$ versus $66.6 \%$, stage $4 ; 35 \%$ versus $100 \%, p=0.04$ ). In the MACIS staging system, 20-year survival rates are determined and comparison should not be made due to insufficient follow-up period in this study. When compared to the EORTC staging system, stage 3 and stage 4 patients' results were determined different (stage $3 ; 51 \%$ versus $100 \%$, stage $4 ; 33 \%$ versus $50 \%, p=0.02$ ). The most consistent results in terms of prognosis was determined in comparison with the TNM staging system (stage $1 ; 100 \%$ versus $97.8 \%$, stage $4 ; 45.3 \%$ versus $50 \%)$.

Conclusion: Many classification systems are proposed for well-differentiated thyroid cancer, to predict the behavior of the tumor. In this study, we concluded that for determination of prognosis in well-differentiated thyroid cancer, the TNM staging system could best predict prognosis consistent with clinical findings.

Key Words: Thyroid cancer, staging systems, prognosis

\section{INTRODUCTION}

Thyroid cancer is the most common endocrine malignancy, accounts for less than $1 \%$ of malignancies diagnosed, and is slowly progressing (1,2). Although survival is generally good, they cause more death than all endocrine organ cancers. Six out of every 1 million people die due to thyroid cancer. Approximately $85 \%$ of thyroid cancers are papillary thyroid cancer. Despite high survival rates, local recurrence and metastases may occur in some patients and this may require a more aggressive surgical treatment. In order to predict tumor behavior many classifications are proposed for differentiated thyroid cancer. Tumor, node, metastasis (TNM) scoring system is a method used for comparing thyroid cancer cases for clinical and pathologic aspects within different centers and recommended by American Joint Committee on Cancer (AJCC) $(3,4)$. The prognosis of patients with well-differentiated thyroid cancer can be predicted by TNM, De Groot, MACIS (metastasis, age, completeness of surgery, invasion of cancer, size) and the European Organization for Research on Treatment of Cancer (EORTC) classifications. After an initial preoperative evaluation, these patients should be re-evaluated postoperatively, taking into account the same criteria $(5,6)$. The three most important variables in all studies are patient age, presence/absence of local invasion and distant metastasis. Nonresectable tumors also have a poor prognosis. local invasion of thyroid capsule and the surrounding tissues increase mortality 10 -fold as compared to intrathyroidal tumors (1). This study aimed to determine the significance of the staging systems (EORTC, De Groot, MACIS, and TNM) on the prognosis of well-differentiated thyroid cancer patients who underwent surgery in our clinics.

\section{MATERIAL AND METHODS}

This retrospective study included 181 patients, who were operated between December 1995 and December 2007 and diagnosed with thyroid cancer, with available inpatient records, and recurrence and survival data. Patients were evaluated in terms of age, gender and MACIS (metastases, Age, Completeness of resection, Invasion, Size) (7) staging system proposed by the Mayo clinic, TNM $(3,4)$ by the AJCC, EORTC (European Organization for Research and Treatment of Cancer) (8) by the European Cancer Research and Treatment Union and De Groot (9) staging systems (Table 1-4). In this study, $7^{\text {th }}$ revision of the TNM staging system were used (4). 
To obtain data for staging, a computer program with an application for PDA (personal digital assistant/palmtop computer) was developed to facilitate parameter entrance. This program was compatible with at least Windows Mobile operating system 2003 (Fig. 1a, b).

Patients were divided into two groups as $\leq 45$ and $>45$ years. Seventy-two of the patients (39.8\%) were equal to or under 45 years of age and 109 patients (60.2\%) were over 45 years. When patients were divided into two groups as male and female, out of the total 181 patients 42 were men (23.2\%) and 139 were women (76.8\%). The follow-up period of the study population was 3.1-14.9 years (median: 13.6 years, mean: 7.08 years). 114 out of 181 patients (63\%) underwent total thyroidectomy, 27 patients (15\%) received near total thyroidectomy, and 40 patients (22\%) had a completion thyroidectomy. On histopathology evaluation of the patients 164 (90.6\%) papillary carcinoma, 14 (7.7\%) follicular cancer, 2 (1.1\%) well-differentiated thyroid cancer (non-papillary or follicular), and one $(0.6 \%)$ Hurthle cell carcinoma was detected. When analyzed according to pathologic tumor size; $68(37.6 \%) \leq 1 \mathrm{~cm}$, 60 (33.2\%) 1.1-2 cm, 26 (14.3\%) $2.1-3 \mathrm{~cm}, 10$ (5.5\%) 3.1-4 cm, $4(2.2 \%) 4.1-5 \mathrm{~cm}$, and $13(7.2 \%)>5 \mathrm{~cm}$ tumors were identified. Patients were divided into two groups according to the presence of multicentricity. 41 patients (22.6\%) were identified with multiple cancer foci. Patients were divided into 4 groups

\section{Table 1. MACIS staging system}

$\begin{array}{lc}\text { Group } & \text { 20-year mortality (\%) } \\ \text { Group } 1=<6.0 & 0.9 \\ \text { Group 2=6.0-6.99 } & 11.3 \\ \text { Group 3=7.0-7.99 } & 44.4 \\ \text { Group 4=>8.0 } & 76.5\end{array}$

Total score $=3.1$ (if age $<39$ ), $0.08 \times$ age (if age $>40$ ),$+0.3 \times$ tumor diameter $\mathrm{cm}$, +1 (if incomplete resection), +1 (if local invasive), +3 (if distant metastasis)

Table 2. TNM Staging System

$\begin{array}{lc}\text { Stage } & \text { 5-year survival (\%) } \\ \text { Stage } 1 & 100 \\ \text { Stage } 2 & 100 \\ \text { Stage } 3 & 95.8 \\ \text { Stage } 4(\mathrm{~A}, \mathrm{~B}, \mathrm{C}) & 45.3\end{array}$

Table 3. EORTC Staging System

$$
\text { Stage } 5 \text { year survival rate (\%) }
$$

Stage 1 (score $<50)$

Stage 2 (score 50-65) 80

Stage 3 (score 66-83) 51

Stage 4 (score 84-108)

51

Stage 5 (score $>108$ )

5

Total score=patient age,+12 (if male), +10 (if poor differentiated folicular thyroid cancer), +10 (if invaded to thyroid capsule), +15 (if 1 distant metastasis is present) +30 (if 2 or more distant metastasis are present) according to histopathologic tumor invasion: 1) no invasion: 2) invasion of surrounding tissues: 3) vascular invasion: 4) capsular invasion. Out of 181 patients, 152 (84\%) were in group 1, 8 $(4.4 \%)$ in group 2, $6(3.3 \%)$ in group 3 and $15(8.3 \%)$ in group 4.

\section{Statistical analysis}

Statistical analysis of data was done by SPSS (version 19.0) statistical software. Survival data were analyzed by Kaplan-Meier method.

\section{RESULTS}

10-year cancer-specific survival rates were evaluated according to De Groot staging system, and the rates of this study were compared to the predicted rates by De Groot staging. The results of patients with stage 1 and stage 2 were compatible with each other, whereas rates of patients with stage 3 and 4 showed difference (grade 3, $87 \%$ versus $66.6 \%$, stage $4,35 \%$ versus $100 \%)$ (Table 5$)(p=0.04)$. Best cancer-specific survival rates were determined in patients with stage 4 and 1 , and the worst rates in patients with stage 3 .

MACIS staging system determines the 20-year survival rate, and comparisons could not be made because of inadequate follow-up period in this study.

The 5-year cancer-specific survival rates were evaluated according to European Organization for Research on Treatment of Cancer staging system, and the rates of this study were compared to the predicted rates by EORTC staging. Rates of stage 3 and stage 4 patients were found to be different (stage $3 ; 51 \%$ versus $100 \%$, stage $4,33 \%$ versus $50 \%$ ). EORTC staging system divided patients into 4 groups, the best 5-year cancer-

\section{Table 4. De Groot staging system}

\section{Stage $\quad 10$ year cancer related survival (\%)}

Stage 1 ; limited to thyroid gland $\quad 100$

Stage 2; locoregional lymph

node involvement 100

$\begin{array}{ll}\text { Stage 3; extrathyroid invasion } & 87 \\ \text { Stage 4; distant metastasis } & 35\end{array}$

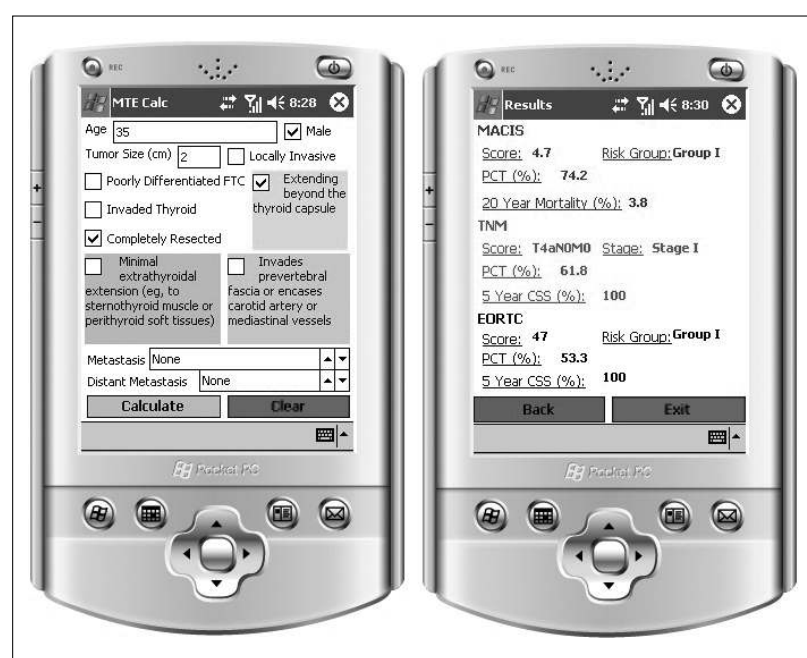

Figure 1a, b. Computer application for PDA 
specific survival rates were identified in stage 2 and 3 patients, and the worst 5 and 10-year cancer-specific survival rates were identified in stage 4 patients (Table 6$)(p=0.02)$.

The 5-year cancer-specific survival rates were evaluated according to Tumor, node, metastasis staging system, and this study rates were compared to the predicted rates by TNM staging. Out of the 6 subgroups of patients, the best 5 -year cancer-specific survival rates were determined in stage 2 and 3 patients, and the worst rates at stage $4 \mathrm{c}$. The most consistent results in terms of prognosis were identified in the comparison with the TNM staging system (stage $1100 \%$ to $97.8 \%$, stage 4 $45.3 \%$ to $50 \%$ ) (Table 7 ).

\section{DISCUSSION}

Well-differentiated thyroid cancer, when detected early and treated appropriately, is a disease with generally good prognosis. The identification of risk factors that affect tumor recurrence and mortality in thyroid cancer is very important in terms determining methods of treatment, and follow-up. In many studies, most of which are retrospective studies, different prognostic factors have been shown to have effects on recurrence and mortality of thyroid cancer. Based on these prognostic factors, 17 prognostic scoring systems were developed to identify patient risk groups.

Tumor staging is an integral part of cancer treatment, providing accurate prognostic information to both the treating physician and the patient. However, which current staging system gives the most accurate prognostic information remains unclear. 8 of 17 current staging systems is used only for papillary thyroid cancer, and 9 staging systems can be used for 2 histological type (papillary and follicular thyroid cancer) or for all histological types (10). In this study, currently the most common used staging systems, De Groot, MACIS (only for papillary thyroid cancer staging), EORTC and TNM (can be used in all histologic subtypes) were evaluated.

University of Chicago, or De Groot Staging, is a clinical classification and was based on the results of 269 papillary thyroid

Table 5. Results according to De Groot staging system (10 year cancer related survival)

\begin{tabular}{|lcc|}
\hline De Groot & De Groot et al. (9) (\%) & Present study (\%) \\
\hline Stage 1 & 100 & 98 \\
\hline Stage 2 & 100 & 96.3 \\
\hline Stage 3 & 87 & 66.6 \\
\hline Stage 4 & 35 & 100 \\
\hline
\end{tabular}

Table 6. Results according to EORTC (5 year cancer related survival)

\begin{tabular}{|ccc|}
\hline EORTC & Byar et al. (8) (\%) & Present study (\%) \\
\hline Stage 1 & 95 & 96.6 \\
\hline Stage 2 & 80 & 100 \\
\hline Stage 3 & 51 & 100 \\
\hline Stage 4 & 33 & 50 \\
\hline
\end{tabular}

cancer patients in 1990, and was later introduced for follicular thyroid carcinoma in 1995 (9). The exclusion of age in this classification seems to be its most important downfall. When results of this study were compared with the results of De Groot staging system following rates were determined; stage 1,98\%$100 \%$, stage $2,96.3 \%-100 \%$, stage $3 ; 66.6 \%-87 \%$ and stage 4 $100 \%-35 \%$, respectively. In this study, according to De Groot staging system patients were divided into 4 groups and best cancer-specific survival rates were determined in patients with stage 1 , and the worst rates in patients with stage 3.

In 1993, the Mayo Clinic, following evaluation of 1779 patients with papillary thyroid cancer (11), defined the MACIS staging system. The main reason for the description of MACIS scoring system is the inability to determine tumor stage according to AGES scoring system in many clinics, which was also defined by the same clinic in 1987. In this study according to the MACIS staging system patients were divided into 4 groups, the best cancer-specific survival rates were detected in patients with stage 1 , and the worst rates in patients with stage 4 . MACIS staging system determines the 20-year survival rate, and since follow-up period in this study was inadequate, comparisons could not be made.

American Joint Committee on Cancer (AJCC) and the International Union Against Cancer Committee (UICC) developed TNM staging system available for each type of cancer. The first TNM staging system was defined in 1940 and its $7^{\text {th }}$ revision was introduced finally in 2010 (4). With this staging that defines " $\mathrm{T}$ " for tumor, " $\mathrm{N}$ " for nodular spread and " $\mathrm{M}$ " for metastasis, staging of disease and monitoring its progression was standardized all over the world. When results of this study were compared with the TNM staging system results the following rates were determined, stage $1 ; 97.8 \%-100 \%$, stage 2 ; $100 \%-100 \%$, stage $3 ; 100 \%-95.8 \%$ and stage $4 c ; 50 \%-45.3 \%$, respectively. Divided into 6 subgroups according to the TNM staging system, the best 5-year cancer-specific survival rates were detected in patients with stage 2 and 3, and the worst rates in stage 4c. The TNM system is being revised for every cancer location, in light of new developments, and the two most recent revisions were made in 2002 and 2010 (3, 4). In the latest 2010 revision, T3NOMO for medullary thyroid cancer was downgraded from stage III to stage II, T1 was divided into two subgroups of $\mathrm{T} 1 \mathrm{a}$ and $\mathrm{T} 1 \mathrm{~b}$ and the term resectable has been changed to moderately advanced, and non-resectable to very-advanced (4).

Covering all histological types of thyroid cancer, the EORTC staging system was first published in 1979. This system was developed based on the results of 507 patients with an average follow-up of 40 months and aimed to stage all histologi-

Table 7. Results according to TNM staging system (5 year cancer related survival)

\begin{tabular}{|lcc|}
\hline TNM & Edge et al. (4) (\%) & Present study (\%) \\
\hline Stage 1 & 100 & 97.8 \\
\hline Stage 2 & 100 & 100 \\
\hline Stage 3 & 95.8 & 100 \\
\hline Stage 4c & 45.3 & 50 \\
\hline
\end{tabular}


cal types of thyroid cancer (8). When this study results were compared to the results of EORTC staging system the rates were, stage $1 ; 96.6 \%-95 \%$, stage $2 ; 100 \%-80 \%$, stage $3 ; 100 \%$ $51 \%$ and stage $450 \%-33 \%$, respectively. In our study, EORTC staging system divided patients into 4 groups, the best 5 -year cancer-specific survival rates were identified in stage 2 and 3 patients, and the worst 5 and 10-year cancer-specific survival rates were identified in stage 4 patients.

Correct staging of thyroid cancer is necessary for the determination of prognosis and type of appropriate treatment. Presence of metastatic disease, unlike many other types of cancer, does not prevent the excision of the primary tumor in differentiated thyroid carcinoma. The metastatic disease may respond to radioactive iodine (RAl) therapy. The extraction of primary tumor and regional metastases together with thyroid tissue is an important component of initial treatment, especially in patients with metastatic differentiated thyroid cancer. postoperative staging of thyroid cancer is used to determine prognosis of a patient with thyroid cancer, decisions for adjuvant treatment such as RAI therapy and TSH suppression therapy, to determine the frequency of recurrence and mortality, and frequency of follow-up, and to ensure accurate communication between health care professionals. Staging systems also enable the evaluation of various treatment strategies in clinical trials for comparable groups (4).

\section{CONCLUSION}

When determining treatment strategies in patients with thyroid cancer, in order to determine prognosis accurately, the loco-regional risk scoring should be determined in the most accurate and the most consistent way with patient clinic. Therefore, using available classification systems, it should be determined if the patient belongs to a low or high-risk group. The patient's level of risk is an important factor in determining proper treatment. Therefore, in determining methods of treatment and follow-up protocol, based on our study results, the TNM staging system has been identified as predicting prognosis most compatible with the clinic, we believe it to be superior to other staging systems.

Peer-review: Externally peer-reviewed.
Author Contributions: Study concept and design - V.E., Ö.M., M.A.; Acquisition of data - V.E., Ö.M., M.A., G.I., M.Y., Y.E., T.K., Ü.Y.; Analysis and interpretation of data - V.E., Ö.M., M.A., G.I., M.Y., T.K.; Preparation of the manuscript - V.E., Ö.M.; Statistical analysis - T.K.

Conflict of Interest: No conflict of interest was declared by the authors.

Financial Disclosure: The authors declared that this study has received no financial support.

\section{REFERENCES}

1. Sakorafas GH, Giotakis J, Stafyla V. Papillary thyroid microcarcinoma: a surgical perspective. Cancer Treat Rev 2005; 31: 423-38. [CrossRef]

2. Biersack HJ, Grünwald F. Thyroid Cancer. Second edition, Springer Verlag Berlin Heidelberg New York 2005: 1-21. [CrossRef]

3. Greene FL, Page DL, Fleming ID. AJCC Cancer Staging Handbook: TNM Classification of malignant Tumors, 6th ed. New York: Springer-Verlag, 2002. [CrossRef]

4. Edge SB, Byrd DR, Compton CC, Fritz AG, Greene FL, Trotti A, editors. AJCC cancer staging manual (7th ed). New York, NY: Springer; 2010: 87-96.

5. Kukora JS. Tiroid Kanseri. Cameron JL (ed). Current Surgical Treatment-1. Avrupa Tıp Kitapçılık. İstanbul 2001; 11: 583-9.

6. Cady B MD. Predictors of Thyroid Tumor Aggressiveness. Clark OH, Duh OY (ed) Textbook of Endocrine Surgery. WB Saunders. Philadelphia.1997; 26: 197-216.

7. Hay ID, Grant CS, van Heerden JA, Goellner JR, Ebersold JR, Bergstralh EJ. Papillary thyroid microcarcinoma: a study of 535 cases observed in a 50-year period. Surgery 1992; 112: 1139-46.

8. Byar DP, Green SB, Dor P, Williams ED, Colon J, van Gilse HA, et al. A prognostic index for thyroid carcinoma. A study of the E.O.R.T.C. Thyroid Cancer Cooperative Group. Eur J Cancer 1979; 15: 103341. [CrossRef]

9. DeGroot LJ, Kaplan EL, Shukla MS, Salti G, Straus FH. Morbidity and mortality in follicular thyroid cancer. Journal of Clinical Endocrinology and Metabolism 1995; 80: 2946-53. [CrossRef]

10. Lang BH, Lo CY, Chan WF, Lam KY, Wan KY. Staging systems for papillary thyroid carcinoma: a review and comparison. Ann Surg 2007; 245: 366-78. [CrossRef]

11. Hay ID, Bergstralh EJ, Goellner JR, Ebersold JR, Grant CS. Predicting outcome in papillary thyroid carcinoma: development of a reliable prognostic scoring system in a cohort of 1779 patients surgically treated at one institution during 1940 through 1989 . Surgery 1993; 114: 1050-8. 